\title{
Detection of intrapartum fetal hypoxia using admission test (AT)
}

\author{
Geeta Gurung, Ashma Rana, Kanti Giri \\ Dept Ob/Gyn, TU Teaching Hospital, Kathmandu, Nepal.
}

\begin{abstract}
:
Objective: The purpose of the present study is to find out the effectiveness of admission test (AT) in detecting fetal hypoxia in labour and to correlate the results of AT with perinatal outcome.

Methods: This was a prospective study, conducted in the department of Ob/Gyn, TU, Teaching Hospital. A total of 100 women in labour were selected for the study. All of them were subjected to Admission test which is 15-20 minutes recording of fetal heart rate and uterine contractions on cardiotocograph machine at the time of admission in labour. The result of AT were not revealed to concerned Obstetrician in labour room and the labouring women and the results of the test were evaluated after delivery so that the clinical management is not changed according to the AT result.

Result: The results of AT were: Reactive in $73 \%$, Equivocal in $23 \%$ and Ominous in $4 \%$. Women with reactive AT had low risk of developing intraapartum fetal distress (1\%) as compared to $4.3 \%$ of equivocal and $50 \%$ of ominous group. Operative delivery for fetal distress was required in only $1.4 \%$ of reactive group in comparison to $4.3 \%$ of equivocal and $50 \%$ of ominous group. Resuscitation was required in $1.4 \%$ of reactive group, $8.7 \%$ of equivocal and $25 \%$ of ominous group. Four babies required neonatal unit and NICU admission for neonatal sepsis (2 from reactive, 2 from equivocal group) and none suffered from intranatal hypoxia.
\end{abstract}

Conclusion: The AT seems to be useful to detect fetal distress already present at admission and seems to have some predictive value for fetal well being for the next few hours of labour.

Key words: Admission test, Cardiotocograph, fetal heart rate, fetal distress, fetal hypoxia, perinatal outcome.

\section{Introduction}

The birth of a healthy baby is the main aim of the parents and the obstetrician involved in her care. It is understood that the most crucial time for the fetus is labour. Even a normal fetus through out pregnancy may sustain hypoxia during labour. So the concept of intrapartum fetal monitoring was conceived and the easiest way was by listening to fetal heart rate. Till the middle of the twentieth century the monitoring was done by fetal growth measured by symphysio-fundal height, movement of the fetus perceived by the mother and listening fetal heart rate. As time went by these methods were not found to be reliable, as mothers do not perceive all the fetal movements and fetal heart rate could be normal if not taken properly during and after contractions. During late1940s and early 1950s it more or less became obvious that intermittent FHR monitoring was not satisfactory method to detect likelihood of fetal compromise. In this respect the cardiotocography for fetal monitoring was invented for which the credit goes to Prof E. H. Hon and Prof. Caldeyro Barcia. ${ }^{1}$ As the cardiotocograph was invented in 1970s continuous fetal monitoring was introduced and became standard practice in all women. Although continuous fetal monitoring is being used extensively in the western countries it is not feasible in most of the developing countries like ours due to economic constraints. So Ingemarsson et al ${ }^{2}$ have described an alternative method of monitoring fetal heart rate during labour. This includes a short recording of FHR and uterine contractions (15-20 minutes) at the time of admission in labour and named as ADMISSION TEST (AT). AT has been categorized as reactive or normal, suspicious or equivocal and ominous (FIGO, 1987).

Reactive or normal tracings are those, which have two accelerations in 20 minutes, traces with no accelerations but normal baseline variability (10-20 beats/min), normal baseline rate with early decelerations but with accelerations. (Fig. 1) 


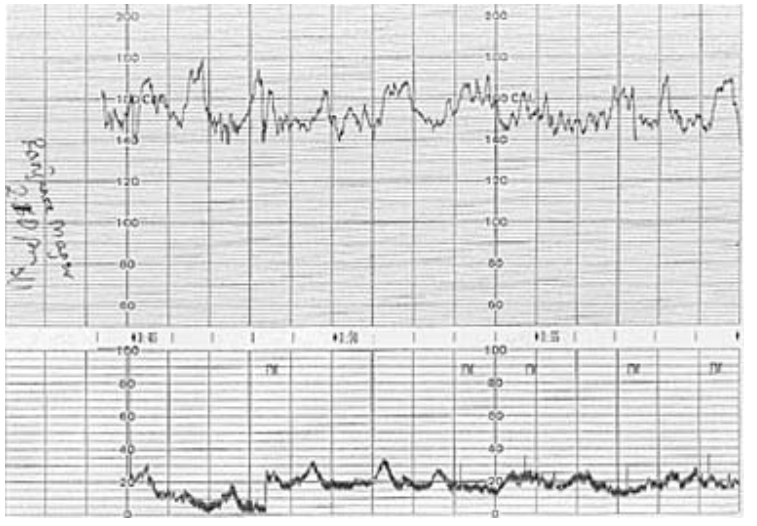

Fig 1. Normal baseline rate with early decelerations

Equivocal /suspicious tracings are those with normal baseline rate with no accelerations in 20 minutes and reduced baseline variability $(5-10$ beats $/ \mathrm{min}$ )or tracings showing abnormal baseline rate with no accelerations and variable decelerations without ominous signs. (Fig.2)

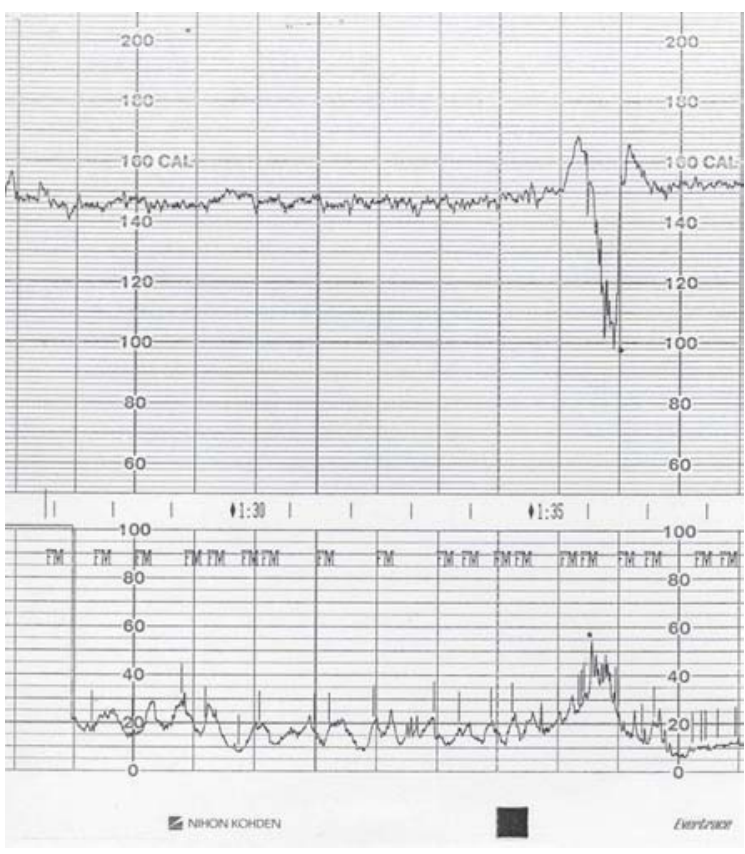

Fig 2. Equivocal/suspicious AT

Ominous tracings are those with baseline variability of less than 5 beats/min and abnormal base line rate. Repeated late decelerations or repeated variable decelerations with any of the following ominous signs: like duration greater than 60 seconds and deceleration greater than 60 beats from the base line heart rate, rebound tachycardia, slow recovery and reduced variability between decelerations are late component of the ominous CTG. (fig.3)

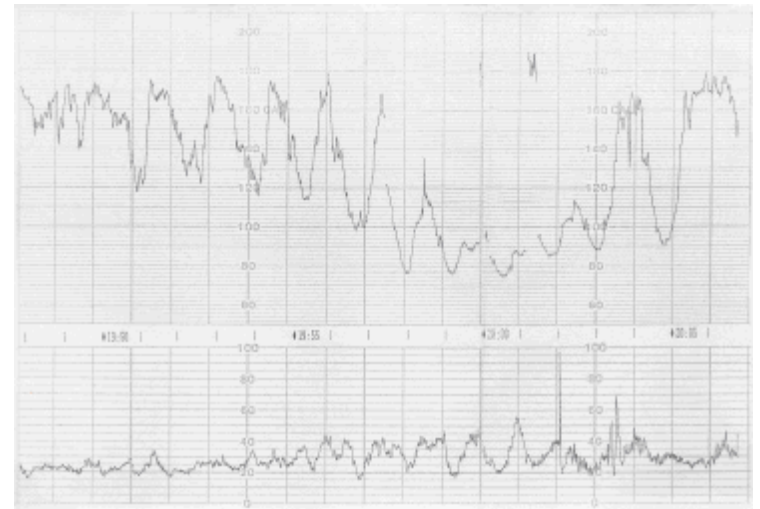

Fig 3. Ominous AT

\section{Material and methods}

It was a prospective study done in the department of $\mathrm{Ob} / \mathrm{Gyn}, \mathrm{TUTH}$. A total of 100 pregnant women who came in labour were randomly selected for the study and informed consent was taken. All the singleton pregnancy irrespective of risk factors were included. Women with IUFD, congenital malformations, multiple pregnancy abnormal lie and presentation, abruptio placentae, cord prolapse, scar rupture needing immediate caesarean section were excluded from the study. On admission, after determining the stage of labour admission test was done using cardiotocograph machine, model no. OMF-8106 (S. no. 00591-6A), Nihon Koden, Japan with the record paper speed of $1 \mathrm{~cm} / \mathrm{min}$. The CTG tracing result was not revealed to the doctors in labour room so that the clinical management will not be changed according to AT. After finishing the admission test women were transferred to first stage room and continued fetal monitoring with intermittent auscultation every 15-30 minutes in first stage and 510 minutes in second stage. After delivery perinatal outcome was assessed by need for operative delivery for fetal distress, colour of liquor, Apgar score, admission to neonatal unit / NICU, neonatal seizures and neonatal death.

\section{Result}

A total of 100 women in labour irrespective of risk factor were studied. The mean age of the mothers was $23.7 \pm$ 3.24 SD in years. More of them (68\%) were primigravida and $32 \%$ were multigravida. More than half $(52 \%)$ were between 40-42 weeks of gestation, $41 \%$ were at 37 completed weeks to 39 weeks and 3 were of unknown LMP.

Of the total 100 women $73 \%$ had reactive, $23 \%$ equivocal and $4 \%$ had ominous AT. 
As shown in table 1. fetal distress was more common in ominous group $(50 \%)$ followed by $4.34 \%$ in equivocal group and $1.4 \%$ in reactive AT and this was statistically significant between reactive and ominous $\mathrm{AT}(\mathrm{P}=$ $0,0006)$. The incidence of vaginal delivery was more common in reactive group $(91.8 \%)$ followed by $56.5 \%$ in equivocal group and $50 \%$ in ominous group. LSCS delivery for fetal distress was observed in $50 \%(\mathrm{n}=2)$ in ominous group $4.3 \%(\mathrm{n}=1)$ in equivocal group and none in reactive group (Table 2 ).

There is no statistically significant difference in three groups regarding the colour of liquor.

In 1 min Apgar score there was no statistically significant difference in the three groups where as in 5 minutes score the difference between reactive and ominous group was significant $(\mathrm{P}=0,00)$ (Table 3 ).

Resuscitation was required for 1 baby $(25 \%)$ in ominous group, $2(8.7 \%)$ in equivocal group and lastly $1(1.4 \%)$ in reactive group.

There were 2 babies (2.7\%) from reactive group and 2 $(8.7 \%)$ from equivocal group who needed neonatal unit/ NICU admission but none of them were due to fetal hypoxia but due to sepsis.

None of the babies developed neonatal seizure or succumbed to death.

Table 1. AT results and Fetal Distress (FD)

\begin{tabular}{|c|c|c|c|}
\hline & Reactive $(n=73)$ & Equivocal $(n=23)$ & Ominous $(n=4)$ \\
\hline Fetal distress (FD) & $1(1.4 \%)$ & $1(4.34 \%)$ & $2(50 \%)$ \\
\hline
\end{tabular}

Table 2: AT results and mode of delivery

\begin{tabular}{lccc}
\hline Mode of delivery & Reactive $(\mathrm{n}=73)$ & Equivocal $(\mathrm{n}=23)$ & Ominous $(\mathrm{n}=4)$ \\
Total vaginal delivery & $67(91.8 \%)$ & $13(56.6 \%)$ & $2(50 \%)$ \\
With fetal distress (FD) & 0 & 0 & 0 \\
Without fetal distress (FD) & $67(91.8 \%)$ & $13(56.6 \%)$ & $2(50 \%)$ \\
\hline Total LSCS & $4(5.5 \%)$ & $9(39.1 \%)$ & $(50 \%)$ \\
With FD & 0 & $1(4.3 \%)$ & 0 \\
Without FD & $4(5.5 \%)$ & $8(34.7 \%)$ & 0 \\
\hline Total instrumental delivery & $2(2.7 \%)$ & $1(4.3 \%)$ & 0 \\
With FD & $1(1.4 \%)$ & 0 & 0 \\
Without FD & $1(1.4 \%)$ & $1(4.3 \%)$ & 0 \\
\hline
\end{tabular}

Table 3: AT results and neonatal outcome.

\begin{tabular}{|c|c|c|c|}
\hline Colour of liquor & Reactive $(n=73)$ & Equivocal $(n=23)$ & Ominous $(n=4)$ \\
\hline Clear & $60(82.2 \%)$ & $17(73.9 \%)$ & $3(75 \%)$ \\
\hline thin meconium & $7(9.6 \%)$ & $0(0 \%)$ & - \\
\hline moderate meconium & $5(6.8 \%)$ & $2(8.7 \%)$ & $1(25 \%)$ \\
\hline Thick meconium & $1(1.4 \%)$ & $2(8.7 \%)$ & - \\
\hline Apgar score $<7$ & Reactive $(n=73)$ & Equivocal $(\mathrm{n}=23)$ & Ominous $(n=4)$ \\
\hline At $1 \mathrm{~min}$ & $7(9.6 \%)$ & $5(21.7 \%)$ & $2(50 \%)$ \\
\hline \multirow[t]{2}{*}{ At $5 \mathrm{~min}$} & 0 & 0 & $1(25 \%)$ \\
\hline & Reactive $(n=73)$ & Equivocal $(n=23)$ & Ominous $(n=4)$ \\
\hline Resuscitation required & $1(1.4 \%)$ & $2(8.7 \%)$ & $1(25 \%)$ \\
\hline Neonatal unit/ NICU admission & $2(2.4 \%)$ & $2(8.7 \%)$ & \\
\hline
\end{tabular}




\section{Discussion}

Among the hundred women in labour who were included in the study $73 \%$ had reactive, $23 \%$ had equivocal and $4 \%$ had ominous AT result. Four babies developed fetal distress $1(1.4 \%)$ from reactive, $1(4.3 \%)$ from equivocal and $2(50 \%)$ from ominous group. Present study including similar other studies ${ }^{2,3}$ showed that women with reactive AT had low risk of developing intrapartum fetal hypoxia and distress and significantly more common in ominous group. Among the 4 fetuses $3(75 \%)$ developed distress within 6 hours ( 1 hour, 3 hour and 6 hours ) and the fourth one developed in 11 hours in second stage of labour. Our finding was supported by other studies ${ }^{2,4}$ in which fetal distress was developed in 6 \& 5 hours respectively after AT. Operative delivery for fetal distress was significantly less in reactive group ( $1.4 \%$ forceps delivery) followed by equivocal group (4.3\% LSCS) and $50 \%$ in ominous group (LSCS). Similar findings have been found by other studies done by different authors. ${ }^{2,4,5}$ From the present study it is noted that there is no difference between the colour of liquor in the three groups as Abramovici et al ${ }^{6}$ and Miller FC et $\mathrm{al}^{7}$ disregarded the importance of intrapartum meconium as a sign of hypoxia.

Observation shows that $100 \%$ of babies from reactive and equivocal group had Apgar score of e" 7 in five minutes where as $50 \%$ from the ominous group had d" 7 Apgar score which is statistically significant and is similar to the studies done by Ingemarsson ${ }^{2}$ and Krebs et al. ${ }^{8}$ Neonatal resuscitation was required in $1.4 \%$ of reactive, $7.8 \%$ in equivocal and $25 \%$ in ominous AT group. This finding denotes low risk babies according to AT required less resuscitation than ominous group. Four babies ( 2 from reactive, 2 from equivocal) required neonatal unit / NICU admission, but all of them for neonatal sepsis not for hypoxia. None of them suffered from neonatal seizures and no neonatal death was observed in the study group.
Overall the women with equivocal and ominous AT had shown to develop more fetal distress and more of operative delivery for fetal distress indicating the need for more intensive fetal monitoring during labour. However AT will not predict the small number of obstetric accidents like cord prolapse and abruption placentae that occur during labour.

\section{Conclusion}

The test seems to be useful to detect fetal distress already present during admission and it seems to give some predictive value for fetal well being for the next few hours of labour.

\section{References}

1. Caldeyro-Barcia R, Alvarez H, Reynolds SRM. Surg. Gynec. Obstet 1950; 91: 641.

2. Ingemarsson I, Arulkumaron S, Ingemarsson E, Tambiraja RJ, Ratnam SS. Admission Test: A screening test for distress in labor. Am J Obstet Gynecol 1986; 68: 800-6.

3. Libiran MJ, Solis MS, Santos RS, Baga EB. Admission Test as a predictor of intrauterine asphyxia. Philipp J Obstet Gynecol 1999; 23 (4): 143-9.

4. Kulkarni AA, Shroti AN. Admission Test: A predictive test for distress in high risk labor. J Obstet Gynecol Res 1998; 24 (4): 255-9.

5. Bhat RA. Labour admission test: A screening tool. Obs \& Gynae Today 2006; 9 (6): 328-31.

6. Abramovici H, Brandes JM, Fuchs K et al. Meconium during delivery: A sign of compensated distress. Am J Obstet Gynecol 1974; 118-25.

7. Miller FC, Sacks DA, Yeh SY et al. Significance of meconium during labour. Am J Obstet Gynecol $1975 ; 122,573$.

8. Krebs HB, Petties RB, Dunn LJ et al. Intrapartum heart rate monitoring. Multifactorial analysis of intrapartum heart rate tracing. Am J Obstet Gynecol 1979; 13:173. 